\title{
Single-Step Combined Laparoscopic Management of Hepatocellular Carcinoma with Simultaneous Radio Frequency Ablation and Trans-Arterial Embolization in Unresactable Lesions
}

\author{
Lukman Cheraghvandi, Michael Silva, Charlie Cheng, Mauro Montalbano, Ali Shirafkan, \\ Cristiana Rastellini, Luca Cicalese*
}

Department of Surgery, University of Texas Medical Branch, Galveston, TX, USA

Email: *lucicale@utmb.edu

How to cite this paper: Cheraghvandi, L., Silva, M., Cheng, C., Montalbano, M., Shirafkan, A., Rastellini, C. and Cicalese, L. (2016) Single-Step Combined Laparoscopic Management of Hepatocellular Carcinoma with Simultaneous Radio Frequency Ablation and Trans-Arterial Embolization in Unresactable Lesions. Journal of Cancer Therapy, 7, 979-985.

http://dx.doi.org/10.4236/jct.2016.713095

Received: October 19, 2016

Accepted: November 30, 2016

Published: December 2, 2016

Copyright (c) 2016 by authors and Scientific Research Publishing Inc. This work is licensed under the Creative Commons Attribution International License (CC BY 4.0).

http://creativecommons.org/licenses/by/4.0/

\begin{abstract}
Hepatocellular carcinoma (HCC) is a cancer with increasing incidence in the USA and high mortality rate. HCC is often difficult to treat due to underlying comorbidities such as cirrhosis. However, the application of loco-regional thermal ablation using radio frequency (RF) and trans-arterial embolization with chemotherapy (TACE) or without (TAE) has shown promising results in the treatment of patients not amenable to surgical resection or liver transplantation. Conventionally, RF and TAE are performed in two separated sessions or two steps and often RF ablation is performed percutaneously. However, no consensus has been reached regarding the ideal interval between the two treatments. In this article, we discuss the feasibility and benefits of a single-step TAE in combination with laparoscopic RF ablation in one operative session. We also present a case where this procedure has been successfully performed demonstrating its feasibility. We suggest that the use of laparoscopic RF ablation in the same surgical session as TAE is feasible and potentially offers several advantages over the two-step process that is usually performed with embolization followed by percutaneous RF with a long time interval. In this article we discuss such advantages.
\end{abstract}

\section{Keywords}

Single Step, Single Session, Hepatocellular Carcinoma, Laparoscopic, Radiofrequency Ablation, Trans-Arterial Embolization

\section{Introduction}

Hepatocellular carcinoma (HCC) is the third leading cause of cancer-related mortality 
worldwide [1] [2] [3]. Along with HCC's frequent association with chronic liver diseases and cirrhosis, its indolent nature and the consequent late diagnosis pose a significant challenge in the treatment.

The choice of treatment for HCC is based on the degree of liver damage, the number and location of tumors, tumor size and patient's physical status [4] [5]. Surgical resection and liver transplantation are the definitive cures in the operable cases, which unfortunately, excludes the majority of HCC patients [5]. A combination of locoregional therapies relying mainly on imaging guidance for targeting of the tumor, including percutaneous, laparoscopic and catheter based techniques, has been used with comparable survival to surgery in small size tumors [6] [7] [8] [9]. However, these procedures usually take place in a two-step manner with trans-arterial embolization (TAE) or trans-arterial chemo-embolization (TACE), usually followed by percutaneous RF ablation a few weeks to months later [7] [8] [10] [11] [12]. In addition to the possible complications of percutaneous RF such as pneumothorax, intraperitoneal bleeding and incomplete target acquisition, these multistep procedures require multiple hospitalizations, tests, anesthesia, prolonged recovery time and increased costs. A minimally invasive surgical approach, laparoscopic RF has also been used and offers several advantages over the percutaneous route [13] [14]. We hypothesize that a possible alternative method would be performing the TAE or TACE and laparoscopic RF simultaneously in a single step or single session with the advantages of shortening length of the treatment, lowering cost, and potentially increasing the efficacy of the treatment. At this time, there are only few reports of the application of these modalities in one-step and have been only reported to be performed all percutaneously [12] [15] [16] [17].

In our practice, we perform RF ablation of HCC lesions surgically using the laparoscopic minimally invasive approach. This approach allows for obtaining a better tumor staging since the surgeon can visualize and biopsying small sub-capsular lesions or peritoneal tumor implants not otherwise visible via CT or MRI imaging. Furthermore, the laparoscopic approach reduces the risk of hemorrhage allowing cauterization of bleeding under direct visualization and limits thermal injury of adjacent structures and organs because the insufflation of $\mathrm{CO}_{2}$ to induce pneumo-peritoneum creates a physical separation between these structures and the liver. Moreover, it has been shown that surgical ultrasound (US) guided RF ablation might offer an improved targeting of the lesion compared to a percutaneous approach as reported in the literature [18] [19] [20].

In this report, we presented our experience using a single step, surgical laparoscopic approach with tans-arterial embolization and RF ablation of the liver tumor in a patient who did not qualify for liver transplant or liver resection.

\section{Case Description}

A 62-year-old male with liver cirrhosis secondary to chronic HCV (Hepatitis C virus), history of nephrectomy due to a gunshot wound and recent history of shortness of breath suspected interstitial lung disease and pulmonary hypertension had a $5 \mathrm{~cm}$ lesion in segment VII of his liver and elevated levels of alpha fetoprotein (AFP). Triple phase CT scan 
was equivocal for contrast enhancement and washout. MR study with and without contrast confirmed an equivocal enhancement pattern. Patient liver function tests (summarized in Table 1) and other lab values revealed a total bilirubin of $2.7 \mathrm{mg} / \mathrm{dl}$, Child Pugh score of 7 and MELD score of 11. Patient underwent laparoscopy and HCC was confirmed with intraoperative US guided biopsy of the lesion. While the patient was anesthetized in the operating room, TAE of the lesion was performed from a femoral approach cannulating the celiac artery and the tertiary arteries supplying the tumor using 8 metallic micro-coils $(3 \times 2 \mathrm{~mm})$ by the vascular surgery team. Once the TAE procedure was completed, laparoscopic RF ablation of the lesion was performed immediately after using RF interstitial tissue ablation (RITA; Starburst system; Angiodynamics) for a $6 \mathrm{~cm}$ area under Ultra sound US guidance. The postoperative course was uneventful. The LFTs temporarily increased after surgery and returned to baseline values after 5 days. The patient was discharged from the hospital 72 hours after the procedure. At one month follow up after surgery, the patient had stable LFTs that remained similar to preoperative baseline levels (Table 1). Additional follow up was not performed by the surgical team due to transferring the patient to another service and location.

\section{Discussion}

HCC is an aggressive neoplasm, with highly neo-angiogenic activity, heavily dependent on arterial blood supply and resilient to currently available chemotherapeutic agents. Only a small percentage of patients are amenable to transplantation or surgical resection. According to current guideline, when these tumors are not treatable with these methods, different modalities have been utilized based on number, size and the extent of the tumor growth as well as liver function and reserve [5] [21]. RF has been established as one of the most promising loco-regional therapies for treating early stage HCC [22] [23]. RF ablation is performed advancing a special electrode into the tumor under US, CT or MRI guidance this can be achieved either percutaneously or laparoscopically. The major constrain of percutaneous RF is the limitation in target acquisition (i.e. lack of direct visualization of tumors and limited accessibility to certain tumor locations, such as the dome of the liver or caudate lobe) and possible complications associated with it (pneumothorax, pleural effusion, neoplastic seeding etc.) [13]. These factors may be also responsible for the variation in the rate of recurrences [24] [25] [26] [27]. The advantages of laparoscopic RF are several and include the direct visualization, better access improving target acquisition, accurate hemostasis, separation of structures to reduce thermal injury, and better staging of the disease by direct visual and US examination of the liver and peritoneum, which allows biopsy of suspicious lesions and also

Table 1. Pre and Post operative Patients liver function tests up to 30 days after surgery.

\begin{tabular}{ccccccc}
\hline Liver Function tests & Pre-op & SURGERY & Day 1+ & Day 2+ & $3+$ & Day 30+ \\
\hline Total Bilirubin $(\mathrm{mg} / \mathrm{dl})$ & 2.1 & 2.7 & 2.5 & 2.6 & 3.4 & 2.1 \\
AST (Ref: $13-40 \mathrm{U} / \mathrm{L})$ & 172 & 147 & 257 & 611 & 397 & 90 \\
ALT (Ref: $9-51 \mathrm{U} / \mathrm{L})$ & 31 & 44 & 53 & 98 & 77 & 36 \\
\hline
\end{tabular}


treating the new lesions all intra-operatively [14] [18] [19] [20].

A 0.5 to $2 \mathrm{~cm}$ safety margin ablation around the tumor has been suggested to reduce the risk of recurrence [28]. Therefore, the application of RF ablation in larger lesions $(>3 \mathrm{~cm})$ has shown possible limitations in achieving full necrosis of the tumor especially at the periphery [29] [30]. However, the currently available probes used for RF can obtain an area of ablation up to $7 \mathrm{~cm}$ (Starburst, RITA) suggesting that even larger lesions can be treated. Since ablative treatments using RF have been recently reported to be comparable to resection for tumor control, in some cases RF treatments can be considered a curative treatment [22] [31].

No consensus exists on the time interval between combined TAE and RF ablation. Studies in animal models suggest that simultaneous TAE and RF increase tumor necrosis area comparing to longer intervals [32] [33] [34]. The method of combining TACE/TAE and percutaneous RF in a single step to obtain the optimum synergistic effects has been reported to reduce the recurrence rate compared to either modality separately in humans [8] [11] [12] [35]. Additionally, patients have benefitted from increased survival rates with nearly similar adverse effects to either of these modalities alone [31].

Based on these data, one-step approach with a combination of TAE (or TACE) with laparoscopic RF should offer the over mentioned advantages and potentially allow extending the current limits of the ablation area thereby increasing the size of tumor that can be treated. Embolization by vascular occlusion of the arterial supply of the tumor area also increases the effect of thermal ablation because of reduced heat sink effect [32].

This is particularly important for cirrhotic patients since the functional reserve is limited. Anatomic surgical resection (lobectomy) of the tumor will inevitably lead to removing significant amount of functional tissue increasing the risk of liver failure. Therefore, functional parenchyma should be spared as much as possible and laparoscopic RF ablation can safely accomplish that while efficiently destroying the tumor tissue. This proposed minimally invasive laparoscopic single-step TAE plus RF approach has the potential advantage to destroy even large tumors while preserving most of the parenchyma, and could be an alternative approach for HCC treatment over conventional resection.

Currently, these procedures are performed by surgeons or interventional radiologists and usually in a multistep approach scheduled at different sessions. The time from diagnosis to treatment by this multistep method can take weeks or months, a delay that might lead to further tumor progression [16] [17].

Recently, it has been shown that these procedures can be safely performed in single-step approach using the percutaneous route [16] [17] However, the percutaneous approach is associated with the limitations previously described. Therefore, we evaluated the feasibility of a similar approach using the laparoscopic technique.

In the case reported hereto, we did not encounter surgical or technical limitations to perform TAE and RF in a single surgical session. The patient tolerated the procedures well and was discharged from the hospital in 72 hours with only a transient elevation of the liver function tests that returned to baseline shortly after and remained stable. This 
case reported demonstrates the feasibility of this single step, multimodality laparoscopic approach as an option in the management of HCC.

\section{Conclusion}

Single-step TAE (or TACE) and RF management of HCC in cirrhotic patients may confer a faster, more efficient and cost-effective method compared to the current multistep practice. We believe that the laparoscopic route of accomplishing this one step modality offers additional benefits and we have shown that it is feasible. However, additional studies to demonstrate these advantages and a possible survival benefit of single-step TAE (or TACE) in combination with laparoscopic RF compared to a percutaneous approach should be entertained.

\section{Conflict of Interest}

The authors declare that they have no conflict of interest.

\section{Acknowledgements}

The authors would like to sincerely thank Ms. Eileen. F. Figueroa and Ms. Paula Porter for their assistance in preparation of this manuscript.

\section{References}

[1] Parkin, D.M., Bray, F., Ferlay, J. and Pisani, P. (2005) Global Cancer Statistic, 2002. $C A: A$ Cancer Journal for Clinicians, 55, 74-108.

[2] Ryerson, A.B., et al. (2016) Annual Report to the Nation on the Status of Cancer, 19752012, Featuring the Increasing Incidence of Liver Cancer. Cancer, 122, 1312-1337. https://doi.org/10.1002/cncr.29936

[3] Laursen, L. (2014) A Preventable Cancer. Nature, 516, S2-S3. https://doi.org/10.1038/516S2a

[4] Makuuchi, M., et al. (2010) Clinical Practice Guidelines for Hepatocellular CarcinomaThe Japan Society of Hepatology 2009 Update. Hepatology Research, 40, 2-144.

[5] Alejandro Forner, M.G., Bruix, J. and Raoul, J.-L. (2014) Treatment of Intermediate-Stage Hepatocellular Carcinoma. Nature Reviews Clinical Oncology, 11, 525-535. https://doi.org/10.1038/nrclinonc.2014.122

[6] Yamakado, K., et al. (2008) Early-Stage Hepatocellular Carcinoma: Radiofrequency Ablation Combined with Chemoembolization versus Hepatectomy. Radiology, 247, 260-266. https://doi.org/10.1148/radiol.2471070818

[7] Lin, S., Hoffmann, K. and Schemmer, P. (2012) Treatment of Hepatocellular Carcinoma: A Systematic Review. Liver Cancer, 1, 144-158. https://doi.org/10.1159/000343828

[8] Kagawa, T., et al. (2010) Transcatheter Arterial Chemoembolization plus Radiofrequency Ablation Therapy for Early Stage Hepatocellular Carcinoma: Comparison with Surgical Resection. Cancer, 116, 3638-3644. https://doi.org/10.1002/cncr.25142

[9] Iezzi, R., et al. (2016) Combined Locoregional Treatment of Patients with Hepatocellular Carcinoma: State of the Art. World Journal of Gastroenterology, 22, 1935-1942. https://doi.org/10.3748/wjg.v22.i6.1935

[10] Tsochatzis, E.A., Germani, G. and Burroughs, A.K. (2010) Transarterial Chemoemboliza- 
tion, Transarterial Chemotherapy, and Intra-Arterial Chemotherapy for Hepatocellular Carcinoma Treatment. Seminars in Oncology, 37, 89-93.

https://doi.org/10.1053/j.seminoncol.2010.03.007

[11] Tang, C.W., Shen, J., Feng, W.M., et al. (2016) Combination Therapy of Radiofrequency Ablation and Transarterial Chemoembolization for Unresectable Hepatocellular Carcinoma: A Retrospective Study. Medicine, 95, e3754.

[12] Bonomo, G., et al. (2012) Combined Therapies for the Treatment of Technically Unresectable Liver Malignancies: Bland Embolization and Radiofrequency Thermal Ablation within the Same Session. Cardiovascular and Interventional Radiology, 35, 1372-1379. https://doi.org/10.1007/s00270-012-0341-0

[13] Minami, Y. and Kudo, M. (2011) Radiofrequency Ablation of Hepatocellular Carcinoma: A Literature Review. International Journal of Hepatology, 2011, Article ID: 104685.

[14] Sánchez-López, A., Pallisera-Lloveras, A., Saiz-Mendiguren, R., et al. (2015) Laparoscopic Radiofrequency Ablation for Hepatocellular Carcinoma. Hepatoma Research, 1.

[15] Kang, S.G., et al. (2009) Single-Session Combined Therapy with Chemoembolization and Radiofrequency Ablation in Hepatocellular Carcinoma Less than or Equal to $5 \mathrm{~cm}$ : A Preliminary Study. Journal of Vascular and Interventional Radiology, 20, 1570-1577. https://doi.org/10.1016/j.jvir.2009.09.003

[16] Gadaleta, C., Catino, A., Ranieri, G., Fazio, V., Gadaleta-Caldarola, G., Cramarossa, A., et al. (2009) Single-Step Therapy-Feasibility and Safety of Simultaneous Transarterial Chemoembolization and Radiofrequency Ablation for Hepatic Malignancies. In Vivo, 23, 813820.

[17] Iezzi, R., Cesario, V., Siciliani, L., Campanale, M., De Gaetano, A.M., Siciliano, M., et al. (2013) Single-Step Multimodal Locoregional Treatment for Unresectable Hepatocellular Carcinoma: Balloon-Occluded Percutaneous Radiofrequency Thermal Ablation (BO-RFA) plus Transcatheter Arterial Chemoembolization (TACE). La Radiologia Medica, 118, 555569. https://doi.org/10.1007/s11547-012-0914-7

[18] Jung, M.K., Lee, J.H., Kim, T.S., Kim, H.S., Cho, C.M., Tak, W.Y., et al. (2002) [Laparoscopic and Percutaneous Ultrasound Guided Radiofrequency Ablation for Hepatocellular Carcinoma: A Preliminary Study]. Taehan Kan Hakhoe Chi, 8, 209-217.

[19] Lee, S.D., Han, H.-S., Cho, J.Y., Yoon, Y.-S., Hwang, D.W., Jung, K., et al. (2012) Safety and Efficacy of Laparoscopic Radiofrequency Ablation for Hepatic Malignancies. Journal of the Korean Surgical Society, 83, 36-42. https://doi.org/10.4174/jkss.2012.83.1.36

[20] Herbold, T., Wahba, R., Bangard, C., Demir, M., Drebber, U. and Stippel, D.L. (2013) The Laparoscopic Approach for Radiofrequency Ablation of Hepatocellular Carcinoma-Indication, Technique and Results. Langenbeck's Archives of Surgery, 398, 47-53. https://doi.org/10.1007/s00423-012-1018-5

[21] Kitai, S., Kudo, M., Izumi, N., Kaneko, S., Ku, Y., Kokudo, N., Sakamoto, M., Takayama, T., Nakashima, O., Kadoya, M., Matsuyama, Y. and Matsunaga, T. (2014) For the Liver Cancer Study Group, Validation of Three Staging Systems for Hepatocellular Carcinoma (JIS Score, Biomarker-Combined JIS Score and BCLC System) in 4,649 Cases from a Japanese Nationwide Survey. Digestive Diseases, 32, 717-724.

[22] Lee, D.H., Lee, J.M., Lee, J.Y., Kim, S.H., Yoon, J.H., Kim, Y.J., Han, J.K. and Choi, B.I. (2014) Radiofrequency Ablation of Hepatocellular Carcinoma as First-Line Treatment: Long-Term Results and Prognostic Factors in 162 Patients with Cirrhosis. Radiology, 270, 900-909. https://doi.org/10.1148/radiol.13130940

[23] Lau, W.Y. and Lai, E.C. (2009) The Current Role of Radiofrequency Ablation in the Man- 
agement of Hepatocellular Carcinoma: A Systematic Review. Annals of Surgery, 249, 20-25. https://doi.org/10.1097/SLA.0b013e31818eec29

[24] Curley, S.A., Izzo, F., Delrio, P., Ellis, L.M., Granchi, J., Vallone, P., et al. (1999) Radiofrequency Ablation of Unresectable Primary and Metastatic Hepatic Malignancies: Results in 123 Patients. Annals of Surgery, 230, 1-8. https://doi.org/10.1097/00000658-199907000-00001

[25] Pawlik, T.M., Izzo, F., Cohen, D.S., Morris, J.S. and Curley, S.A. (2003) Combined Resection and Radiofrequency Ablation for Advanced Hepatic Malignancies: Results in $172 \mathrm{~Pa}-$ tients. Annals of Surgical Oncology, 10, 1059-1069.

https://doi.org/10.1245/ASO.2003.03.026

[26] Kuvshinoff, B.W. and Ota, D.M. (2002) Radiofrequency Ablation of Liver Tumors: Influence of Technique and Tumor Size. Surgery, 132, 605-611. Discussion 611-2. https://doi.org/10.1067/msy.2002.127545

[27] Mulier, S., Ni, Y.C., Jamart, J., Ruers, T., Marchal, G. and Michel, L. (2005) Local Recurrence after Hepatic Radiofrequency Coagulation: Multivariate Meta-Analysis and Review of Contributing Factors. Annals of Surgery, 242, 158-171. https://doi.org/10.1097/01.sla.0000171032.99149.fe

[28] Hocquelet, A., Trillaud, H., Frulio, N., Papadopoulos, P., Balageas, P., Salut, C., et al. (2016) Three-Dimensional Measurement of Hepatocellular Carcinoma Ablation Zones and Margins for Predicting Local Tumor Progression. Journal of Vascular and Interventional Radiology, 27, 1038-1045.e2.

[29] Yamasaki, T., Kurokawa, F., Shirahashi, H., Kusano, N., Hironaka, K. and Okita, K. (2002) Percutaneous Radiofrequency Ablation Therapy for Patients with Hepatocellular Carcinoma during Occlusion of Hepatic Blood Flow. Comparison with Standard Percutaneous Radiofrequency Ablation Therapy. Cancer, 95, 2353-2360. https://doi.org/10.1002/cncr.10966

[30] Kim, Y.S., Rhim, H., Cho, O.K., Koh, B.H. and Kim, Y. (2006) Intrahepatic Recurrence after Percutaneous Radiofrequency Ablation of Hepatocellular Carcinoma: Analysis of the Pattern and Risk Factors. European Journal of Radiology, 59, 432-441. https://doi.org/10.1016/j.ejrad.2006.03.007

[31] Chen, Q.W., Ying, H.-F., Gao, S., Shen, Y.-H., Meng, Z.-Q., Chen, H., et al. (2016) Radiofrequency Ablation plus Chemoembolization versus Radiofrequency Ablation Alone for Hepatocellular Carcinoma: A Systematic Review and Meta-Analysis. Clinics and Research in Hepatology and Gastroenterology, 40, 309-314.

https://doi.org/10.1016/j.clinre.2015.07.008

[32] Goldberg, S.N. (2001) Radiofrequency Tumor Ablation: Principles and Techniques. European Journal of Ultrasound, 13, 129-147. https://doi.org/10.1016/S0929-8266(01)00126-4

[33] Lee, I.J., Kim, Y.I., Kim, K.W., Kim, D.H., Ryoo, I., Lee, M.W., et al. (2012) Radiofrequency Ablation Combined with Transcatheter Arterial Embolisation in Rabbit Liver: Investigation of the Ablation Zone according to the Time Interval between the Two Therapies. British Journal of Radiology, 85, E987-E994. https://doi.org/10.1259/bjr/90024696

[34] Nakai, M., Sato, M., Sahara, S., Kawai, N., Tanihata, H., Kimura, M., et al. (2007) Radiofrequency Ablation in a Porcine Liver Model: Effects of Transcatheter Arterial Embolization with Iodized Oil on Ablation Time, Maximum Output, and Coagulation Diameter as well as Angiographic Characteristics. World Journal of Gastroenterology, 28, 2841-2845.

[35] Gurusamy, K., Tsochatzis, E., Thorburn, D. and Davidson, B.R. (2015) Management of People with Early or very Early Stage Hepatocellular Carcinoma: A Network Meta-Analysis. Cochrane Database of Systematic Reviews, No. 4, Article No. CD011650. https://doi.org/10.1002/14651858.cd011650 
Submit or recommend next manuscript to SCIRP and we will provide best service for you:

Accepting pre-submission inquiries through Email, Facebook, LinkedIn, Twitter, etc. A wide selection of journals (inclusive of 9 subjects, more than 200 journals)

Providing 24-hour high-quality service

User-friendly online submission system

Fair and swift peer-review system

Efficient typesetting and proofreading procedure

Display of the result of downloads and visits, as well as the number of cited articles

Maximum dissemination of your research work

Submit your manuscript at: http://papersubmission.scirp.org/

Or contact jct@scirp.org 